\title{
Diversidade funcional de bactérias isoladas de solos rizosférico e não rizosférico em cultura de milho
}

\author{
Functional diversity of bacteria isolated from rhizosphere and non-rhizosphere soils under maize \\ cultivation
}

Rodrigo Ferraz Ramos, Lisiane Sobucki, Bruna Rohrig, Juliane Ludwig \& Daniel Joner Daroit*

Universidade Federal da Fronteira Sul, Cerro Largo, RS, Brasil. *Autor para correspondência: djdaroit@gmail.com.

Submissão: 09/03/2017 / Aceite: 13/06/2018

\begin{abstract}
RESUMO
Este estudo avaliou os potenciais hidrolítico e de solubilização de fosfato de bactérias isoladas de Latossolo Vermelho cultivado com milho. A coleta de solo rizosférico (SR) e solo não rizosférico (NR) foi realizada, sendo procedido o isolamento de colônias bacterianas em culturas puras. Meios de cultura sólidos foram utilizados na avaliação da produção de hidrolases e solubilização de fosfato pelos isolados. A partir de SR e NR foram isolados 30 e 19 tipos coloniais distintos, respectivamente. De 29 isolados de SR, 68,9\%, 65,5\%, 20,7\% e 24,1\% apresentaram atividade proteolítica, celulolítica, amilolítica e solubilização de fosfato, respectivamente. Dos isolados de NR, 57,9\% produziram celulase, 42,1\% protease, $57,9 \%$ amilase e $21,0 \%$ solubilizaram fosfato; contudo, $31,6 \%$ destes isolados não demonstraram qualquer atividade. Diversas bactérias apresentaram atividades combinadas, representado aproximadamente $58 \%$ dos isolados de SR e NR. Além da relevância ambiental e agrícola, a habilidade microbiana em secretar enzimas relacionadas ao ciclo do carbono e nitrogênio e a solubilização de fosfato podem ser importantes na perspectiva biotecnológica.
\end{abstract}

PALAVRAS-CHAVE: microbiota do solo, enzimas, solubilização de fosfato, bioprospecção.

\begin{abstract}
This study evaluated the hydrolytic and phosphate-solubilizing potentials of soil bacteria isolated from a red latosol (oxisol) under maize cultivation. Rhizosphere soil (SR) and non-rhizosphere soil (NR) were collected and, subsequently, distinct bacterial colonies were isolated in pure cultures. Solid culture media were employed to evaluate production of hydrolases and phosphate solubilization by the isolates. From SR and NR, 30 and 19 distinct colonial types were isolated, respectively. From 29 SR isolates, 68.9\%, 65.5\%, $20.7 \%$ and $24.1 \%$ displayed proteolytic, cellulolytic, amylolytic, and phosphate-solubilizing activities, respectively. From the NR isolates, $57.9 \%$ produced cellulase, $42.1 \%$ protease, $57.9 \%$ amylase and $21.0 \%$ solubilized phosphate; however, $31.6 \%$ of these isolates did not display any activity. Diverse bacteria presented combined activities, representing about $58 \%$ of the SR and NR isolates. In addition to environmental and agricultural relevance, the microbial ability to secrete enzymes related to carbon and nitrogen cycles and phosphate solubilization might be important from a biotechnological perspective.
\end{abstract}

KEYWORDS: soil microbiota, enzymes, phosphate solubilization, bioprospecting.

\section{INTRODUÇÃO}

Os serviços ambientais prestados pelos solos nos (agro)ecossistemas são, em grande parte, realizados por organismos vivos. A biota e a biodiversidade dos solos vêm recebendo crescente atenção por sua participação na funcionalidade e sustentabilidade dos solos. A microbiota é a principal responsável pelas reações bioquímicas relacionadas à transformação da matéria orgânica, intemperismo de rochas, entre outros, participando da gênese do solo e atuando como reguladora de nutrientes, especialmente através de processos de decomposição e ciclagem de elementos (ARIAS et al. 2005, MOREIRA \& SIQUEIRA 2006, ANDREOLA \& FERNANDES 2007).

Devido ao caráter insolúvel e macromolecular da maioria dos componentes orgânicos, sua decomposição necessita da produção de enzimas hidrolíticas extracelulares pela microbiota edáfica (BURNS et al. 2013). Portanto, as enzimas são parte integral da ciclagem de nutrientes, influenciando 
diretamente a fertilidade dos solos, sendo que a maior parte das enzimas no solo tem origem microbiana (BANDICK \& DICK 1999, CENCIANI et al. 2011). Ainda, o fósforo (P) é o segundo nutriente mais limitante ao crescimento vegetal, sendo um elemento de menor mobilidade e, com isso, o menos disponível para absorção pelos vegetais. Neste sentido, a microbiota também pode afetar a fertilidade dos solos atuando na disponibilização de fósforo $(P)$ às plantas através de processos de solubilização de fosfatos inorgânicos e mineralização de fosfatos na forma orgânica (KHAN et al. 2007, SHARMA et al. 2013).

O conhecimento da diversidade microbiana e o potencial enzimático e funcional da microbiota adquirem importância no contexto da qualidade do solo, visto que estão associados à estabilidade do ecossistema frente a distúrbios ambientais naturais ou antrópicos (JURBURG \& SALLES 2015). Da mesma forma, o potencial solubilizador de fosfatos de microrganismos do solo pode implicar em sua utilização na disponibilização de $P$ às plantas através de estratégias no manejo de sistemas agrícolas sustentáveis (GYANESHWAR et al. 2002).

Considerando os distintos atributos entre a rizosfera e solos sem influência de raízes, que atuam na seleção de populações de microrganismos e na determinação de atividades metabólicas microbianas (LI et al. 2014), e o papel fundamental da microbiota na manutenção de processos edáficos, este estudo objetivou isolar bactérias a partir de solo rizosférico e não rizosférico (entrelinhas) na cultura do milho (Zea mays), para então avaliar o potencial hidrolítico e de solubilização de fosfato inorgânico dos isolados bacterianos.

\section{MATERIAL E MÉTODOS}

\section{Coleta de solo rizosférico e não rizosférico e processamento das amostras}

A coleta de amostras de solos de ambiente rizosférico e não rizosférico foi realizada em parcela $(27,5$ $\mathrm{m}^{2}$ ) com cultivo de milho (Zea mays L., híbrido DKB 240 VT PRO ${ }^{\circledR}$ ) em sistema de plantio direto não consolidado, no sul do Brasil, sendo o solo classificado como Latossolo Vermelho distroférrico típico (EMBRAPA 2013). Para o solo rizosférico, plantas $(n=4)$ foram cuidadosamente removidas do solo, e o solo frouxamente aderido às raízes foi removido por agitação manual (TURNBULL et al. 2012). O solo do ambiente rizosférico foi coletado utilizando espátulas estéreis. Quanto ao solo das entrelinhas, subamostras foram coletadas em quatro pontos aleatórios da área (profundidade de 0 a $5 \mathrm{~cm}$ ) e reunidas em uma amostra composta.

As amostras foram homogeneizadas e $10 \mathrm{~g}$ foram adicionados, de forma asséptica, a Erlenmeyers contendo $90 \mathrm{~mL}$ de solução salina $\left(8,5 \mathrm{~g} \mathrm{~L}^{-1}\right)$ estéril e submetidos a agitação orbital (200 rpm) por $20 \mathrm{~min}$ em temperatura ambiente. Posteriormente, diluições decimais em série foram realizadas em solução salina estéril e $100 \mu \mathrm{L}$ de cada diluição foram inoculados por espalhamento, em duplicata, em placas de Petri contendo Ágar Triptona de Soja (TSA; HiMedia, India), as quais foram incubadas a $25^{\circ} \mathrm{C}$ por $72 \mathrm{~h}$. Parte das amostras de solo foi alocada em estufa para secagem a $60^{\circ} \mathrm{C}$, até atingir massa constante (solo seco).

\section{Contagem e isolamento de bactérias}

Após a incubação, placas contendo 20-200 colônias foram utilizadas para contagem de bactérias cultiváveis nas condições empregadas. Os resultados foram expressos em unidades formadoras de colônia por grama de solo seco (UFC $\mathrm{g}^{-1}$ solo seco). Todas as placas com diferentes diluições foram avaliadas quanto à morfologia das colônias bacterianas. Colônias com aspecto morfológico distinto foram selecionadas para isolamento em culturas puras através da técnica de esgotamento em placas de TSA. Os isolados foram mantidos a $4{ }^{\circ} \mathrm{C}$ em TSA, e inoculados em novas placas a cada 45 dias. As bactérias isoladas de solo rizosférico e não rizosférico foram nomeadas utilizando a sigla SR (Solo Rizosférico) e NR (Solo não rizosférico), empregando-se também um número sequencial de 1 a 24 , e de 1 a 15 , respectivamente. Letras $(A, B)$ alocadas após o número indicam tipos coloniais considerados distintos obtidos durante os procedimentos de repique para isolamento.

\section{Caracterização morfológica e coloração de Gram}

As bactérias isoladas foram utilizadas para confeccionar, em triplicata, esfregaços em lâminas para microscopia, que foram submetidos ao protocolo de coloração de Gram (FREITAS \& PICOLI 2007). Os esfregaços foram avaliados utilizando microscópio óptico de campo claro quanto à morfologia celular bacteriana e perfil tintorial obtido.

\section{Avaliação do potencial celulolítico}

Os isolados foram inoculados através de picadas em placas de Ágar Carboximetil Celulose (Ágar $\mathrm{CMC})$ composto por $\mathrm{CMC}\left(5,0 \mathrm{~g} \mathrm{~L}^{-1}\right), \mathrm{NaNO}_{3}\left(2,0 \mathrm{~g} \mathrm{~L}^{-1}\right), \mathrm{K}_{2} \mathrm{HPO}_{4}\left(1,0 \mathrm{~g} \mathrm{~L}^{-1}\right), \mathrm{KCl}\left(0,5 \mathrm{~g} \mathrm{~L}^{-1}\right), \mathrm{MgSO}_{4}\left(0,5 \mathrm{~g} \mathrm{~L}^{-}\right.$ $\left.{ }^{1}\right)$, peptona $\left(0,5 \mathrm{~g} \mathrm{~L}^{-1}\right)$ e ágar $\left(15,0 \mathrm{~g} \mathrm{~L}^{-1}\right)$. Após incubação a $25^{\circ} \mathrm{C}$ por $96 \mathrm{~h}$, as placas foram adicionadas de solução de lugol de Gram. Seguindo-se incubação por 3-5 min, as placas foram visualizadas quanto à presença de halos transparentes, que indicam a produção e atuação de celulases (KASANA et al. 2008). 
Este experimento foi realizado em sextuplicata $(n=6)$.

\section{Avaliação do potencial amilolítico}

Os isolados foram inoculados em placas contendo meio de cultura sólido contendo amido solúvel (SANTOS \& MARTINS 2003), denominado ágar amido. Após incubação a $25^{\circ} \mathrm{C}$ por $96 \mathrm{~h}$, as placas foram adicionadas de solução de lugol de Gram e visualizadas quanto à presença de halos transparentes, que indicam a produção de amilases. Este experimento foi realizado em sextuplicata $(n=6)$.

\section{Avaliação do potencial proteolítico}

Os isolados foram inoculados em picada em placas de ágar leite (AL). Após incubação a $25^{\circ} \mathrm{C}$ por 72 $\mathrm{h}$, as placas foram visualizadas quanto à presença de halos transparentes ao redor das colônias, indicando a produção de proteases (RIFFEL \& BRANDELLI 2006). Este experimento foi realizado em sextuplicata $(n=$ 6).

\section{Avaliação do potencial de solubilização de fosfato inorgânico}

Os isolados foram inoculados em picada em meio de cultura contendo glicose (10 $\left.\mathrm{g} \mathrm{L}^{-1}\right)$, extrato de levedura $\left(0,5 \mathrm{~g} \mathrm{~L}^{-1}\right), \mathrm{Ca}_{3}\left(\mathrm{PO}_{4}\right)_{2}$ (fosfato tricálcico, $\left.4 \mathrm{~g} \mathrm{~L}^{-1}\right)$ e ágar $\left(15 \mathrm{~g} \mathrm{~L}^{-1}\right)$ (SOUCHIE \& ABBOUD 2007). Seguindo-se incubação a $28,5{ }^{\circ} \mathrm{C}$ por 10 dias, as placas foram visualizadas quanto à presença de halos transparentes ao redor das colônias, indicativos da capacidade bacteriana em solubilizar fosfato. Este experimento foi realizado em triplicatas $(n=3)$.

\section{Análise de dados}

Nos ensaios para verificação da atividade hidrolítica (enzimática) e da atividade de solubilização de fosfato, o diâmetro das colônias bacterianas (DMC, em $\mathrm{mm}$ ) e o diâmetro total do halo de hidrólise ou halo de solubilização $(\mathrm{DMH}=$ halo + colônia, em $\mathrm{mm}$ ) foram mensurados utilizando paquímetro digital. Estas mensurações foram utilizadas para o cálculo de índices enzimáticos (IE) e índices de solubilização (IS), conforme OLIVEIRA et al. (2006a,b), através da relação entre DMH e DMC, sendo obtidos pela equação: IE ou IS = DMH/DMC.

Os resultados das repetições foram empregados para cálculo de médias e erro padrão, utilizando o software Microsoft Office Excel 2007 (Microsoft). Para o IE e IS, realizou-se análise estatística utilizando o Sistema para Análise e Separação de Médias em Experimentos Agrícolas (SASM-Agri, versão 8.2 demo) (CANTERI et al. 2001).

\section{RESULTADOS E DISCUSSÃO}

\section{Contagem e isolamento de bactérias}

A contagem de bactérias em solo rizosférico alcançou 1,84 $\pm 0,14 \times 10^{7}$ UFC $\mathrm{g}^{-1}$ solo seco, enquanto que em solo não rizosférico o resultado da densidade de bactérias foi de $1,31 \pm 0,11 \times 10^{7} \mathrm{UFC}^{-1}$ solo seco, sendo esta diferença significativa $(p<0,01)$ pelo teste $t$. Quanto aos tipos coloniais, foram isolados 30 tipos morfológicos em solo rizosférico e 19 a partir de solo não rizosférico (entrelinha). Os resultados demonstraram tendência de maior população e diversidade de bactérias no solo rizosférico em comparação ao solo não rizosférico. Resultados similares foram observados por NAHAS et al. (1997) em solo rizosférico da cultura do repolho. A rizosfera, ambiente formado pelo solo que sofre influência de raízes, é reconhecida como uma zona de elevada atividade microbiana e enzimática em comparação com solos sem estas influências (BANDICK \& DICK 1999, MANHÃES \& FRANCELINO 2013).

$O$ incremento significativo no número e diversidade de bactérias no solo rizosférico pode ser consequência do efeito rizosférico, caracterizado pela estimulação da atividade da comunidade microbiana devido à liberação, pelas raízes, de exsudatos, mucilagens, secreções e lisados celulares contendo açúcares, aminoácidos, vitaminas, ácidos orgânicos, entre outros (CARDOSO \& NOGUEIRA 2007, CORDEIRO et al. 2012). Contudo, estudo na caatinga da zona semiárida do nordeste brasileiro não observou diferenças significativas entre o número de microrganismos no solo e na rizosfera da gramínea Aristida adscensionis (GORLACH-LIRA \& COUTINHO 2007).

\section{Caracterização morfológica e coloração de Gram}

Do total de isolados de solo rizosférico (30), 13 isolados (43,3\%) apresentaram-se como bastonetes Gram-positivos, sete (23,3\%) como cocos Gram-positivos, cinco (16,7\%) como bastonetes Gram-negativos, e cinco (16,7\%) como cocos Gram-negativos. Considerando os 19 isolados de solo não rizosférico, 73,7\% apresentaram morfologia de bastonete, enquanto que $26,3 \%$ apresentaram-se como cocos, sendo que $63,2 \%$ dos isolados foram classificados como Gram-positivos e $36,8 \%$ apresentaram perfil de coloração Gram-negativa. Dos isolados não rizosféricos com forma de bastonete, $64,3 \%$ demonstraram perfil tintorial Gram-positivo; enquanto que dos isolados com forma de coco, $60 \%$ apresentaram perfil de coloração Grampositivo (resultados não mostrados).

$\mathrm{Na}$ rizosfera, devido à seletividade das raízes, podem predominar bactérias Gram-negativas, como 
observado na rizosfera de trigo (FISCHER et al. 2007). No entanto, o número e grupos de bactérias podem ser afetados pelo tipo de solo e de vegetais, práticas de manejo do solo e condições climáticas (SILVA \& NAHAS 2002, VIANA et al. 2011, RAMOS et al. 2012).

AMARANTE et al. (2010), analisando amostras de solo do bioma Amazônia em diferentes profundidades, observaram o predomínio de bactérias do tipo cocos Gram-negativo, representando 81,25\% das ocorrências da população bacteriana. Contudo, em solo rizosférico da caatinga, $16 \%$ dos isolados demonstraram perfil Gram-negativo (todos bastonetes), enquanto que 83\% apresentaram perfil Grampositivo e, destes, $70 \%$ demonstraram forma filamentosa (actinomicetos) e $30 \%$ forma de bastonete (GORLACH-LIRA \& COUTINHO 2007). SILVA \& NAHAS (2002) observaram, em diferentes formas de manejo do solo e cultivares, predomínio de bactérias Gram-positivas $(94,7 \%)$ em comparação com bactérias Gram-negativas (5,3\%), sendo que do total de bactérias Gram-positivas, 97,5\% apresentaram forma de bastonete, e $2,5 \%$ foram de cocos.

\section{Potencial celulolítico}

O potencial celulolítico foi investigado considerando que a lignocelulose é o principal componente da biomassa vegetal. $O$ constituinte mais abundante desta biomassa é a celulose, um polímero linear de moléculas de glicose associadas por ligações glicosídicas $\beta-1,4$. Neste sentido, as celulases são um grupo de enzimas que catalisam a clivagem destas ligações nas moléculas de celulose (MAKI et al. 2009).

Dos 29 isolados bacterianos da rizosfera de milho, 65,5\% (19) produziram halo de hidrólise em Ágar CMC, sendo 68,4\% (13) bactérias Gram-positivas e 31,6\% (6) Gram-negativas, demonstrando a capacidade de secretar enzimas celulolíticas (Tabela 1A). Os isolados SR6A e SR8 apresentaram IE de 5,6, sendo estatisticamente superiores ao demais isolados. O isolado SR15 apresentou atividade celulolítica, entretanto, o crescimento filamentoso neste meio de cultura demonstrou-se impróprio para a avaliação de DMC e DMH. Em solo de entrelinha, dos 19 isolados bacterianos, 57,9\% (11) produziram halo de hidrólise, sendo $72,7 \%$ (8) bactérias Gram-positivas e 27,3\% (3) Gram-negativa (Tabela 2A). O isolado NR8B apresentou IE de 7,6, sendo estatisticamente superior que os demais isolados bacterianos.

De forma importante, alguns isolados de solo não rizosférico (NR2, NR3B, NR8A e NR8B) apresentaram IE elevado (Tabela 2A) em comparação ao isolado SR6A, que demonstrou o maior IE entre os isolados de solo rizosférico (Tabela $1 \mathrm{~A}$ ). Para as bactérias de solo não rizosférico, a indicação de maior capacidade celulolítica em potencial (maior IE) sugere relação com as diferenças na composição nutricional dos ambientes rizosférico e não rizosférico, visto que neste último as principais fontes de carbono e energia para a microbiota heterotrófica derivam da biomassa lignocelulósica no solo (MOREIRA \& SIQUEIRA 2006).

Investigação com bactérias isoladas da rizosfera de cana-de-açúcar indicou que $11,1 \%$ foram capazes de hidrolisar celulose (RODRIGUES et al. 2016). Em solo da Índia, $32 \%$ dos isolados bacterianos apresentaram atividade celulolítica (GHOSH et al. 2007), e percentual similar foi reportado por GORLACHLIRA \& COUTINHO (2007) para 43 bactérias mesofílicas isoladas de solo/rizosfera. OLIVEIRA et al. (2006a), investigando a atividade hidrolítica de rizóbios nativos da Amazônia Central, demonstraram que 9\% dos isolados apresentaram atividade celulolítica; para os mesmos autores, os IE variaram de 1,5 a 2,0. Em avaliação de microrganismos do solo, aproximadamente $85 \%$ dos isolados bacterianos apresentaram produção de celulases e, destes, 19,33\% exibiram halos de hidrólise maiores de 7,0 mm (SANOMIYA \& NAHAS 2003). Percentual similar (85,7\%) de celulolíticos foi repotado por FIGUEROA-LÓPEZ et al. (2016) para 14 bactérias isoladas da rizosfera de milho com efeito antagônico contra Fusarium verticillioides; enquanto que $46 \%$ de 39 bactérias endofíticas de milho demonstraram potencial celulolítico (PEREIRA \& CASTRO, 2014).

\section{Potencial amilolítico}

O amido é o principal componente de reserva dos vegetais. Amilases são enzimas que clivam ligações glicosídicas nas moléculas de amido, liberando dextrinas e pequenos polímeros compostos por unidades de glicose. Estas enzimas são produzidas por plantas, animais e, especialmente, microrganismos, estando amplamente distribuídas nos solos (DAS \& VARMA 2011).

Dos 29 isolados bacterianos da rizosfera avaliados $20,7 \%$ (6) produziram halo de hidrólise (Tabela 1C), sendo $83,3 \%$ (5) bactérias Gram-positivas e 16,7\% (1) Gram-negativa, demonstrando assim a capacidade de secretarem enzimas amilolíticas. O isolado SR8 apresentou IE de 3,1, sendo estaticamente superior aos demais isolados. Em solo não rizosférico, 57,9\% (11) dos isolados produziram halo de hidrólise (Tabela 2C), sendo 72,7\% (8) bactérias Gram-positivas e 27,3\% (3) Gram-negativas, onde os isolados SR3B, SR8A e SR8B apresentaram IE de 3,7, 3,1 e 3,1 respectivamente, sendo estatisticamente superior que os demais isolados. A menor porcentagem de bactérias com capacidade amilolítica no solo rizosférico, em comparação ao solo não rizosférico, pode indicar menor habilidade no uso do amido como fonte de 
carbono e energia, uma vez que carboidratos simples, de baixa massa molecular, são geralmente exsudados pelas raízes (CARDOSO \& NOGUEIRA 2007).

Segundo SANOMIYA \& NAHAS (2003), aproximadamente $30 \%$ das bactérias isoladas de solo apresentaram atividade amilolítica. De 30 isolados bacterianos de solo, $20 \%$ demonstraram potencial produção de amilases (KAUR et al. 2012). OLIVEIRA et al. (2006b) reportaram que 29,7\% de 64 rizóbios isolados apresentaram resultado positivo para atividade amilolítica. A capacidade de hidrolisar amido em cultivos em meio sólido foi observada para $19 \%$ de um total de 38 bactérias isoladas de solo (GHOSH et al. 2007). A partir de bactérias isoladas de pilhas de compostagem, $14 \%$ demonstraram potencial amilolítico através de cultivos em meio sólido contendo amido (PASCON et al. 2011). Contudo, para bactérias mesofílicas isoladas de solo/rizosfera da gramínea Aristida adscensionis, cerca de $60 \%$ demonstaram habilidade de produzir amilases (GORLACH-LIRA \& COUTINHO 2007).

A avaliação do potencial amilolítico dos isolados bacterianos pode refletir seu papel ecológico no solo. Enzimas amilolíticas, juntamente com enzimas celulolíticas, atuam na degradação de resíduos e biomassa vegetais. Logo, a atividade destas enzimas e de seus microrganismos produtores está diretamente associada à ciclagem do carbono nos solos (SHAN et al. 2008, CORDEIRO et al. 2012).

\section{Potencial proteolítico}

Proteases são enzimas que hidrolisam ligações peptídicas em peptídeos e proteínas. Embora estes compostos estejam presentes em menor quantidade no material orgânico no solo, a proteólise é processo importante relacionado à ciclagem de nitrogênio nos ecossistemas, uma vez que é etapa limitante da mineralização do nitrogênio. Logo, microrganismos proteolíticos podem atuar na disponibilização de amônio no solo, que pode então ser oxidado por bactérias nitrificantes, resultando em nitrato, que é a principal forma de nitrogênio absorvida pelos vegetais (MOREIRA \& SIQUEIRA 2006).

Observou-se que $68,9 \%$ (20) dos isolados bacterianos da rizosfera do milho produziram halo de hidrólise em ágar leite (Tabela 1B), demonstrando a capacidade desses isolados em secretar proteases (RIFFEL \& BRANDELLI 2006). O isolado SR15, embora tenha demonstrado atividade proteolítica, apresentou crescimento filamentoso, o que torna imprópria a mensuração de DMH e DMC. O isolado SR21 apresentou IE de 4,2 sendo estatisticamente superior aos demais isolados. Dos isolados bacterianos do solo não rizosférico (Tabela 2B), 42,1\% (8) produziram halo de hidrólise, sendo 75\% (6) Gram-positivas e 25\% (2) Gram-negativas, onde o isolado NR8B apresentou IE de 3,6 sendo estatisticamente superior aos demais isolados bacterianos.

Especificamente para bactérias associadas ao milho, de 14 isolados rizosféricos que apresentaram efeito antagônico contra Fusarium verticillioides, 50\% (7) demonstraram potencial proteolítico (FIGUEROALÓPEZ et al. 2016), e de seis Pseudomonas spp. rizosféricas, quatro (66,7\%) apresentaram capacidade de produzir proteases (DJURIC et al. 2011). Para 39 bactérias endofíticas do milho, proteases foram produzidas por $56 \%$ dos isolados (PEREIRA \& CASTRO 2014).

Mais de 1.200 microrganismos, isolados de diferentes ambientes (solo, raízes, resíduos avícolas), foram avaliados quanto à atividade proteolítica, sendo que 13\% apresentaram a capacidade de produzir proteases extracelulares em AL (JEONG et al. 2010). Em triagem funcional de 38 bactérias isoladas de solo, $76 \%$ dos isolados demonstraram produção de proteases, sendo esta a atividade enzimática mais comumente observada (GHOSH et al. 2007). De forma análoga, 93\% das bactérias $(n=43)$ mesofílicas isoladas de solo/rizosfera apresentaram produção de protease (GORLACH-LIRA \& COUTINHO 2007).

SANOMIYA \& NAHAS (2003), em um Latossolo Vermelho utilizado com diferentes manejos, observaram que $69,9 \%$ dos isolados bacterianos de solo não rizosférico apresentaram atividade proteolítica. OLIVEIRA et al. (2006a) relataram que $28,4 \%$ de um total de 67 isolados de rizóbia apresentaram produção de proteases. Em estudo similar, de 64 rizóbios nativos isolados de solo amazônico utilizando feijão caupi e soja como plantas armadilhas, $35,9 \%$ dos isolados apresentaram atividade proteolítica (OLIVEIRA et al. 2006b). De sete bactérias do gênero Bacillus isoladas a partir da rizosfera de Brachiaria brizantha, para todas foi detectada a produção de proteases (ARAUJO et al. 2012).

\section{Solubilização de fosfato inorgânico}

O potencial de solubilização de fosfato inorgânico das bactérias isoladas de ambiente rizosférico foi avaliado em meio de cultura contendo $\mathrm{Ca}_{3}\left(\mathrm{PO}_{4}\right)_{2}$. Dos 29 isolados bacterianos da rizosfera, 24,1\% (7) produziram halo de solubilização (Tabela 1D), sendo que não ocorreu diferença estatística significativa entre os isolados. Considerando os 19 isolados bacterianos não rizosféricos, 21\% (4) produziram halo de solubilização, não ocorrendo diferença estatística significativa entre os isolados bacterianos (Tabela 2D).

Bactérias solubilizadoras de $P$ vêm sendo encontradas em diferentes nichos nos solos, sendo grande parte isolada a partir de ambientes rizosféricos (GYANESHWAR et al. 2002, SHARMA et al. 2013). A partir de 58 isolados obtidos de raízes de plantas sadias de milho, 27 bactérias $(46,5 \%)$ foram capazes de 
solubilizar fosfato $\left(\mathrm{CaHPO}_{4}\right)$ após 15 dias de cultivo (PEDRINHO et al. 2010). Considerando 292 bactérias rizosféricas de milho isoladas de diferentes áreas do Rio Grande do Sul, 154 (53\%) foram capazes de solubilizar fosfato inorgânico (ARRUDA et al. 2013), enquanto que de 57 isolados bacterianos da rizosfera/rizoplano de milho, 11 (19,3\%) solubilizaram fosfato (MANZOOR et al. 2017).

Tabela 1. Atividades enzimáticas e solubilização de fosfato por bactérias isoladas de solo rizosférico de milho. ${ }^{(1)}$

Table 1. Enzymatic activities and phosphate solubilization by bacteria isolated from rhizosphere soil under maize cultivation.

(A) Celulase

(isolados cultivados em ágar carboximetilcelulose, $\mathrm{pH} 7,0$, a $25{ }^{\circ} \mathrm{C}$ por $96 \mathrm{~h}$ )

\begin{tabular}{|c|c|c|c|c|c|c|c|}
\hline Isolado & $\mathrm{DMH}$ & DMC & $\mathrm{IE}^{(2)}$ & Isolado & $\mathrm{DMH}$ & DMC & $\mathrm{IE}$ \\
\hline SR2 & $19,5 \pm 0,36$ & $7,8 \pm 0,23$ & $2,5^{f}$ & SR9A & $37,6 \pm 1,14$ & $14,6 \pm 1,14$ & 2,6 ef \\
\hline SR3A & $7,2 \pm 0,82$ & $3,4 \pm 0,26$ & $2,1^{\mathrm{fg}}$ & SR9B & $5,4 \pm 0,12$ & $2,1 \pm 0,03$ & 2,5 ef \\
\hline SR3B & $4,4 \pm 0,21$ & $3,6 \pm 0,17$ & $1,2 \mathrm{gh}$ & SR10 & $9,6 \pm 0,10$ & $2,8 \pm 0,05$ & 3,4 de \\
\hline SR4A & $13,8 \pm 0,93$ & $3,8 \pm 0,60$ & $3,6^{\mathrm{cd}}$ & SR12 & $29,7 \pm 1,14$ & $5,9 \pm 0,07$ & $5,0 a b$ \\
\hline SR4B & $9,2 \pm 1,08$ & $4,0 \pm 0,22$ & $2,3^{f}$ & SR15 & POS & POS & POS \\
\hline SR5 & $10,2 \pm 1,05$ & $2,2 \pm 0,04$ & $4,6 \mathrm{bc}$ & SR18 & $3,5 \pm 0,12$ & $2,9 \pm 0,05$ & $1,2 \mathrm{gh}$ \\
\hline SR6A & $30,5 \pm 0,75$ & $5,4 \pm 0,11$ & 5,6 a & SR22 & $15,6 \pm 0,31$ & $3,9 \pm 0,09$ & $4,0 \mathrm{~cd}$ \\
\hline SR6B & $26,2 \pm 2,02$ & $5,2 \pm 0,06$ & $5,0 \mathrm{ab}$ & SR23 & $4,1 \pm 0,12$ & $3,8 \pm 0,12$ & $1,1^{\mathrm{h}}$ \\
\hline SR7B & $13,4 \pm 0,69$ & $3,9 \pm 0,10$ & 3,4 de & SR24 & $7,4 \pm 0,10$ & $3,5 \pm 0,02$ & $2,1 \mathrm{fg}$ \\
\hline SR8 & $26,7 \pm 1,12$ & $4,8 \pm 0,17$ & 5,6 a & & & & \\
\hline
\end{tabular}

(B) Protease

(isolados cultivados em ágar leite, $\mathrm{pH} 7,0$, a $25^{\circ} \mathrm{C}$ por $72 \mathrm{~h}$ )

\begin{tabular}{lrrrrrrr}
\hline \multicolumn{1}{c}{ Isolado } & \multicolumn{1}{c}{$\mathrm{DMH}$} & \multicolumn{1}{c}{$\mathrm{DMC}$} & \multicolumn{1}{c}{$\mathrm{IE}$} & \multicolumn{1}{c}{ Isolado } & \multicolumn{1}{c}{$\mathrm{DMH}$} & \multicolumn{1}{c}{ DMC } & IE \\
\hline SR1 & $28,1 \pm 0,80$ & $11,1 \pm 0,85$ & $2,6^{\text {cde }}$ & SR13 & $19,7 \pm 1,99$ & $11,9 \pm 2,89$ & $1,7^{f}$ \\
SR2 & $22,4 \pm 0,42$ & $12,1 \pm 0,40$ & $1,9^{\text {def }}$ & SR14 & $7,5 \pm 0,18$ & $6,1 \pm 0,20$ & $1,2^{f}$ \\
SR3A & $12,7 \pm 0,72$ & $4,0 \pm 0,35$ & $3,2^{\text {abc }}$ & SR15 & POS & POS & POS \\
SR5 & $17,7 \pm 0,75$ & $6,7 \pm 0,42$ & $2,7^{\text {bcde }}$ & SR16 & $22,1 \pm 2,18$ & $13,5 \pm 1,69$ & $1,7^{\text {def }}$ \\
SR6A & $7,3 \pm 0,37$ & $4,9 \pm 0,19$ & $1,5^{\text {ef }}$ & SR17 & $25,6 \pm 2,41$ & $14,4 \pm 1,30$ & 1,8 def \\
SR7A & $21,5 \pm 1,95$ & $17,9 \pm 1,55$ & $1,2^{f}$ & SR19 & $15,6 \pm 0,55$ & $5,0 \pm 0,14$ & $3,1^{\text {abc }}$ \\
SR8 & $5,3 \pm 0,40$ & $4,6 \pm 0,47$ & $1,1^{f}$ & SR20A & $7,3 \pm 0,67$ & $3,9 \pm 0,13$ & 1,9 def \\
SR9A & $20 \pm 0,50$ & $12,1 \pm 0,55$ & $1,7^{\text {bcde }}$ & SR21 & $22,3 \pm 2,18$ & $5,8 \pm 1,01$ & 4,2 a \\
SR10A & $6,9 \pm 0,59$ & $3,2 \pm 0,15$ & $2,1^{\text {cdef }}$ & SR22 & $23,5 \pm 0,69$ & $6,5 \pm 0,63$ & 3,9 ab \\
SR12 & $28,5 \pm 1,16$ & $16,9 \pm 0,86$ & $1,7^{\text {def }}$ & SR24 & $12,2 \pm 1,20$ & $4,3 \pm 0,20$ & 2,9 bcd \\
\hline
\end{tabular}

(C) Amilase

(isolados cultivados em ágar amido, $\mathrm{pH} 7,0$, a $25^{\circ} \mathrm{C}$ por $96 \mathrm{~h}$ )

\begin{tabular}{|c|c|c|c|c|c|c|c|}
\hline Isolado & $\mathrm{DMH}$ & DMC & IE & Isolado & $\mathrm{DMH}$ & DMC & IE \\
\hline$\overline{\text { SR3A }}$ & $7,0 \pm 0,07$ & $4,6 \pm 0,11$ & $1,5^{c}$ & SR12 & $29,7 \pm 1,32$ & $12,9 \pm 0,39$ & $2,3^{b}$ \\
\hline SR5 & $24,6 \pm 1,48$ & $21,8 \pm 1,33$ & $1,1^{d}$ & SR14 & $12,3 \pm 0,35$ & $8,3 \pm 0,27$ & $1,5^{\mathrm{c}}$ \\
\hline SR8 & $11,5 \pm 0,89$ & $3,7 \pm 0,15$ & $3,1^{a}$ & SR22 & $31,8 \pm 1,66$ & $27,8 \pm 1,32$ & $1,1^{d}$ \\
\hline
\end{tabular}

(D) Solubilização de fosfato

(isolados cultivados em ágar contendo fosfato tricálcico, $\mathrm{pH} 6,0$, a $28,5^{\circ} \mathrm{C}$ por $240 \mathrm{~h}$ )

\begin{tabular}{|c|c|c|c|c|c|c|c|}
\hline Isolado & $\mathrm{DMH}$ & DMC & IS & Isolado & $\mathrm{DMH}$ & DMC & IS \\
\hline SR1 & $5,2 \pm 0,05$ & $5,1 \pm 0,05$ & $1,0^{a}$ & SR17 & $5,1 \pm 0,05$ & $4,4 \pm 0,07$ & $1,2^{a}$ \\
\hline SR3B & $6,8 \pm 0,03$ & $4,8 \pm 0,03$ & $1,4^{\mathrm{a}}$ & SR19 & $4,1 \pm 0,03$ & $3,4 \pm 0,05$ & $1,2^{a}$ \\
\hline SR15 & $6,1 \pm 0,03$ & $5,1 \pm 0,03$ & $1,2^{a}$ & SR22 & $6,2 \pm 0,03$ & $5,8 \pm 0,03$ & $1,1^{\mathrm{a}}$ \\
\hline SR16 & $6,1 \pm 0,05$ & $5,7 \pm 0,05$ & $1,1^{\mathrm{a}}$ & & & & \\
\hline
\end{tabular}

(1) Os resultados são média \pm erro padrão de experimentos realizados em sextuplicata (atividades enzimáticas) ou triplicata (solubilização de fosfato). (2) Para cada atividade avaliada, índices enzimáticos (IE) ou de solubilização de fosfato (IS) seguidos pelas mesmas letras não diferem entre si $(p>0,05)$ pelo Teste de Tukey. $\mathrm{DMH}=$ Diâmetro médio do halo (hidrólise ou solubilização); $\mathrm{DMC}=$ Diâmetro médio da colônia; IE = Índice enzimático; IS = Índice de solubilização; POS: Atividade enzimática positiva (colônias e halos de hidrólise não mensurados devido a crescimento filamentoso do isolado).

De 36 isolados bacterianos obtidos da rizosfera de cana-de-açúcar, $15(41,7 \%)$ solubilizaram fosfato inorgânico (RODRIGUES et al. 2016). Aproximadamente 50\% das bactérias isoladas a partir de raízes de soja apresentaram a capacidade de solubilizar fosfato tricálcico (KUKLINSKY-SOBRAL et al. 2004). Em estudo com 205 rizóbios de solos da Amazônia, 68 isolados (33,2\%) demonstraram capacidade de solubilizar fosfato de cálcio (CHAGAS JÚNIOR et al. 2010).

A solubilização de fosfatos desempenha importante papel no incremento do teor de $P$ na solução do solo e, com isso, na biodisponibilidade para vegetais. Contudo, as populações de microrganismos solubilizadores podem não ser suficientes para que $\mathrm{O} P$ liberado promova substancial incremento do crescimento vegetal. A utilização de microrganismos solubilizadores na forma de inoculantes para as práticas agrícolas representa uma alternativa ambientalmente adequada às aplicações de fertilizantes minerais (KHAN et al. 2007). 
Tabela 2. Atividades enzimáticas e solubilização de fosfato por bactérias isoladas de solo não rizosférico em área com cultivo de milho.(1)

Table 2. Enzymatic activities and phosphate solubilization by bacteria isolated from non-rhizosphere soil under maize cultivation.

(A) Celulase

(isolados cultivados em ágar carboximetilcelulose, $\mathrm{pH} 7,0$, a $25^{\circ} \mathrm{C}$ por $96 \mathrm{~h}$ )

\begin{tabular}{|c|c|c|c|c|c|c|c|}
\hline Isolado & $\mathrm{DMH}$ & DMC & $\mathrm{IE}^{(2)}$ & Isolado & $\mathrm{DMH}$ & DMC & IE \\
\hline NR2 & $36,1 \pm 0,99$ & $5,7 \pm 0,71$ & $6,7^{a b}$ & NR8B & $42,6 \pm 0,49$ & $5,6 \pm 0,13$ & 7,6 a \\
\hline NR3A & $36,1 \pm 0,53$ & $9,7 \pm 0,18$ & $3,7^{d}$ & NR9 & $20,9 \pm 0,28$ & $3,5 \pm 0,09$ & $5,9 \mathrm{bc}$ \\
\hline NR3B & $36,3 \pm 0,37$ & $5,1 \pm 0,11$ & $7,1 \mathrm{ab}$ & NR11 & $12,9 \pm 0,36$ & $3,4 \pm 0,27$ & $3,9^{d}$ \\
\hline NR4 & $32,7 \pm 0,84$ & $7,0 \pm 0,88$ & $4,8^{\mathrm{cd}}$ & NR13 & $34,1 \pm 0,61$ & $8,5 \pm 1,10$ & $4,3^{d}$ \\
\hline NR7B & $15,6 \pm 0,22$ & $8,5 \pm 0,29$ & $1,8^{e}$ & NR15A & $9,7 \pm 0,16$ & $5,9 \pm 0,16$ & $1,6^{\mathrm{e}}$ \\
\hline NR8A & $42,9 \pm 0,48$ & $6,2 \pm 0,36$ & $7,1 \mathrm{ab}$ & & & & \\
\hline
\end{tabular}

(B) Protease

(isolados cultivados em ágar leite, $\mathrm{pH} 7,0$, a $25^{\circ} \mathrm{C}$ por $72 \mathrm{~h}$ )

\begin{tabular}{lrrrlrrr}
\hline \multicolumn{1}{c}{ Isolado } & \multicolumn{1}{c}{$\mathrm{DMH}$} & \multicolumn{1}{c}{ DMC } & \multicolumn{1}{c}{ IE } & Isolado & \multicolumn{1}{c}{ DMH } & \multicolumn{1}{c}{ DMC } & IE \\
\hline NR3A & $11,8 \pm 0,81$ & $10,1 \pm 3,51$ & $1,17^{\mathrm{d}}$ & NR8B & $30,1 \pm 0,69$ & $8,3 \pm 0,79$ & $3,63^{\mathrm{a}}$ \\
NR3B & $9,8 \pm 0,63$ & $7,2 \pm 1,82$ & $1,37^{\mathrm{d}}$ & NR9 & $9,8 \pm 2,27$ & $7,9 \pm 4,67$ & $1,24 \mathrm{~d}$ \\
NR7B & $31,4 \pm 1,23$ & $9,9 \pm 1,35$ & $3,18^{\mathrm{b}}$ & NR13 & $10,8 \pm 0,75$ & $9,1 \pm 1,57$ & $1,20 \mathrm{~d}$ \\
NR8A & $22,7 \pm 0,24$ & $9,7 \pm 1,21$ & $2,34^{\mathrm{c}}$ & NR15A & $22,3 \pm 0,52$ & $10,5 \pm 1,04$ & $2,12^{\mathrm{c}}$ \\
\hline
\end{tabular}

(C) Amilase

(isolados cultivados em ágar amido, $\mathrm{pH} 7,0$, a $25^{\circ} \mathrm{C}$ por $96 \mathrm{~h}$ )

\begin{tabular}{llrrlrrr}
\hline \multicolumn{1}{c}{ Isolado } & \multicolumn{1}{c}{$\mathrm{DMH}$} & \multicolumn{1}{c}{$\mathrm{DMC}$} & \multicolumn{1}{c}{$\mathrm{IE}$} & Isolado & \multicolumn{1}{c}{ DMH } & \multicolumn{1}{c}{ DMC } & \multicolumn{1}{c}{ IE } \\
\hline NR2 & $39,7 \pm 2,24$ & $27,8 \pm 2,72$ & $1,5^{\mathrm{cd}}$ & NR8B & $30,7 \pm 0,72$ & $10,1 \pm 1,07$ & $3,1^{\mathrm{a}}$ \\
NR3A & $43,6 \pm 1,14$ & $37,3 \pm 0,99$ & $1,2^{\mathrm{d}}$ & NR9 & $6,1 \pm 0,24$ & $2,7 \pm 0,04$ & $2,2^{\mathrm{b}}$ \\
NR3B & $23,7 \pm 0,44$ & $6,6 \pm 0,47$ & $3,7^{\mathrm{a}}$ & NR11 & $11,2 \pm 0,59$ & $6,2 \pm 0,21$ & $1,8^{\mathrm{bcd}}$ \\
NR4 & $25,2 \pm 1,12$ & $12,5 \pm 1,20$ & $2,1^{\mathrm{bc}}$ & NR13 & $21,9 \pm 1,89$ & $10,1 \pm 1,32$ & $2,2^{\mathrm{b}}$ \\
NR7B & $23,7 \pm 0,94$ & $18,9 \pm 0,58$ & $1,2^{\mathrm{d}}$ & NR15A & $22,0 \pm 0,24$ & $16,3 \pm 0,21$ & $1,3 \mathrm{~d}$ \\
NR8A & $27,3 \pm 0,76$ & $8,9 \pm 0,34$ & $3,1^{\mathrm{a}}$ & & & & \\
\hline
\end{tabular}

(D) Solubilização de fosfato

(isolados cultivados em ágar contendo fosfato tricálcico, $\mathrm{pH} 6,0$, a $28,5^{\circ} \mathrm{C}$ por $240 \mathrm{~h}$ )

\begin{tabular}{llllllll}
\hline \multicolumn{1}{c}{ Isolado } & $\mathrm{DMH}$ & $\mathrm{DMC}$ & $\mathrm{IS}^{(2)}$ & Isolado & DMH & DMC & IS \\
\hline NR7A & $3,87 \pm 0,03$ & $3,32 \pm 0,03$ & $1,16^{\mathrm{a}}$ & NR11 & $2,72 \pm 0,03$ & $2,42 \pm 0,03$ & $1,12^{\mathrm{a}}$ \\
NR8 & $3,47 \pm 0,03$ & $3,17 \pm 0,03$ & $1,10^{\mathrm{a}}$ & NR14 & $6,37 \pm 0,03$ & $5,52 \pm 0,08$ & $1,15^{\mathrm{a}}$ \\
\hline
\end{tabular}

(1)Os resultados são média \pm erro padrão de experimentos realizados em sextuplicata (atividades enzimáticas) ou triplicata (solubilização de fosfato). ${ }^{(2)}$ Para cada atividade avaliada, índices enzimáticos (IE) ou de solubilização de fosfato (IS) seguidos pelas mesmas letras não diferem entre si $(p>0,05)$ pelo Teste de Tukey. $\mathrm{DMH}=$ diâmetro médio do halo (hidrólise ou solubilização); $\mathrm{DMC}=$ diâmetro médio da colônia; IE = índice enzimático; IS = índice de solubilização.

\section{Atividades combinadas}

As frequências relativas das atividades demonstradas pelos isolados bacterianos de solo rizosférico e de solo não rizosférico foram compiladas na Figura 1. A avaliação das atividades hidrolíticas e de solubilização de fosfato inorgânico das 29 bactérias isoladas da rizosfera de milho indicou que 11 isolados $(37,9 \%)$ apresentaram somente uma dentre as quatro atividades avaliadas, sendo sete bactérias celulolíticas $(24,1 \%)$ e quatro proteolíticas $(13,8 \%)$ (Figura $1 \mathrm{~A})$.

No entanto, $58,6 \%$ das bactérias isoladas de solo rizosférico (17) apresentaram duas ou mais atividades. Neste sentido, 11 isolados $(37,9 \%)$ apresentaram duas atividades, com a combinação celulase + protease sendo a mais frequentemente observada (cinco isolados; 17,2\%). Três atividades foram observadas para cinco isolados bacterianos $(17,2 \%)$, sendo que a combinação celulase + protease + amilase foi apresentada por quatro isolados (13,8\%). Um dos 29 isolados (SR22) demonstrou as quatro atividades investigadas, enquanto que o isolado SR20B não exibiu quaisquer das atividades. Considerando a totalidade dos isolados que apresentaram duas ou mais das atividades estudadas, $37,9 \%$ (11) produziram celulase + protease (Figura 1A).

Em solo não rizosférico $68,4 \%$ dos isolados (11) bacterianos apresentaram pelo menos uma das atividades avaliadas; contudo, $31,6 \%$ dos isolados (6) não demonstraram nenhuma atividade nas condições de ensaio empregadas (Figura 1B). Dois isolados (10,5\%) exibiram uma atividade, representada unicamente pela solubilização de fosfato, e dois isolados (10,5\%) apresentaram duas atividades, demonstrando a combinação celulase + amilase. Oito isolados $(42,1 \%)$ exibiram três atividades combinadas, sendo que a combinação protease + amilase + celulase foi observada para sete isolados $(36,8 \%)$ e um dos 19 isolados de solo não rizosférico (NR8A; 5,3\%) demonstrou as quatro atividades investigadas. Considerando a totalidade dos isolados que apresentaram duas ou mais atividades, $57,9 \%$ (11) produziram celulase + amilase (Figura 1B). 


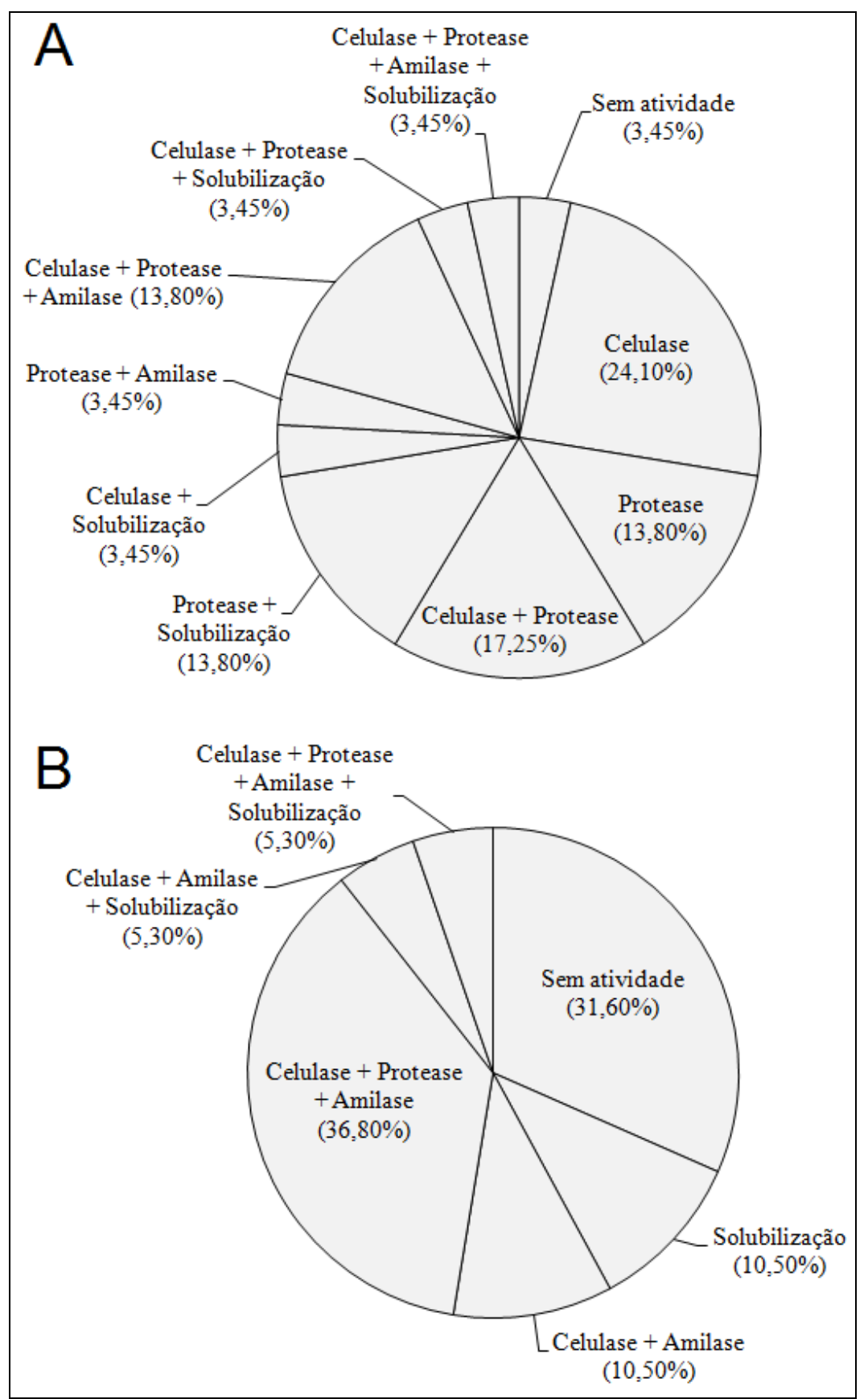

Figura 1. Frequência relativa (\%) das atividades avaliadas, e suas combinações, para (A) 29 isolados bacterianos de solo rizosférico e (B) 19 isolados bacterianos de solo não rizosférico.

Figure 1. Relative frequency (\%) of evaluated activities, and their combinations, for (A) 29 bacterial isolates from rhizosphere soil, and (B) 19 bacterial isolates from non-rhizosphere soil.

De 12 bactérias associadas à rizosfera de milho modificado e não modificado geneticamente, três (25\%) apresentaram produção de celulase, oito $(66,7 \%)$ produção de protease, e sete $(58,3 \%)$ produção de lipase, sendo que dois isolados (16,7\%) demonstraram a produção destas três atividades enzimáticas (AHMAD et al. 2013). Para 11 bactérias rizosféricas isoladas de milho e caracterizadas como solubilizadoras de fosfato inorgânico, duas (18,2\%) apresentaram potencial proteolítico e duas (18,2\%) demonstraram atividade amilolítica, sendo que um destes isolados $(9,1 \%)$ apresentou as três atividades (MANZOOR et al. 2017). Em investigação com seis bactérias endofíticas isoladas de raízes de milho, três $(50 \%)$ produziram celulase, quatro $(66,7 \%)$ amilase, cinco $(83,3 \%)$ protease, e nenhuma foi capaz de solubilizar fosfato inorgânico. Quanto às atividades combinadas, dois isolados $(33,3 \%)$ produziram somente protease, um isolado $(16,7 \%)$ a combinação amilase + protease, um isolado $(16,7 \%)$ a combinação celulase + amilase, e dois isolados (33,3\%) a combinação celulase + amilase + protease (SZILAGYI-ZECCHIN et al. 2014). 
A versatilidade funcional é comumente reportada para vários isolados bacterianos (SANOMIYA \& NAHAS 2003, GORLACH-LIRA \& COUTINHO 2007, TURNBULL et al. 2012, RODRIGUES et al. 2016). Neste sentido, o isolamento de microrganismos não objetiva somente estimar seus números no solo, mas também sua diversidade, incluindo a diversidade funcional, que pode ser determinada pela expressão de diferentes enzimas, por exemplo, relacionadas à utilização de carbono da matéria orgânica (ARIAS et al. 2005).

Tais avaliações podem contribuir para o melhor entendimento de aspectos relativos à importância da atividade da comunidade microbiana e da redundância funcional da microbiota para a dinâmica de processos ecossistêmicos em ambientes naturais e/ou perturbados (JURBURG \& SALLES 2015). Contudo, um dos desafios na investigação da microbiota do solo reside, exatamente, no reconhecimento da conexão entre o comportamento e atividades de organismos isolados e as propriedades ecossistêmicas como a produtividade e resiliência (TURNBULL et al. 2012).

Para além da perspectiva ambiental e agroecológica, enzimas microbianas são amplamente empregadas em diversas aplicações industriais. O mercado mundial de enzimas encontra-se em crescimento e expansão constantes, movimentando bilhões de dólares anualmente. Aproximadamente $85 \%$ das enzimas utilizadas comercialmente são obtidas a partir de microrganismos, explicitando a importância das enzimas microbianas neste cenário (SANCHEZ \& DEMAIN 2011).

\section{CONCLUSÃO}

Em Latossolo Vermelho distroférrico típico cultivado com milho, verificou-se maior densidade e diversidade de bactérias heterotróficas cultiváveis no solo rizosférico do que em solo não rizosférico. As atividades observadas para os isolados bacterianos sugerem que a produção de protease, celulase, amilase e solubilização de fosfato inorgânico são características comuns da microbiota nos dois compartimentos edáficos avaliados.

Através da abordagem experimental utilizada, os resultados indicaram elevada funcionalidade da microbiota rizosférica em comparação à microbiota não rizosférica. A redundância funcional da microbiota investigada pode apresentar relevância em aspectos relativos à dinâmica de processos (agro)ecossistêmicos, além de representar um dos principais recursos do ambiente que pode ser explorado para a elaboração e proposição de produtos e processos biotecnológicos.

\section{REFERÊNCIAS}

AHMAD N et al. 2013. Function and phylogenetic characterization of rhizospheric bacteria associated with GM and non GM maize. Pakistan Journal of Botany 45: 1781-1788.

AMARANTE CB et al. 2010. Diversidade microbiana em solos de Terra Preta Arqueológica. Enciclopédia Biosfera 6: 110.

ANDREOLA F \& FERNANDES SAP. 2007. A microbiota do solo na agricultura orgânica e no manejo das culturas. In: SILVEIRA APD \& FREITAS SS. Microbiota do solo e qualidade ambiental. Campinas: Instituto Agronômico. p.21-37.

ARAUJO FF et al. 2012. Bioprospecção de rizobactérias promotoras de crescimento em Brachiaria brizantha. Revista Brasileira de Zootecnia 41: 521-527.

ARIAS ME et al. 2005. Soil health - a new challenge for microbiologists and chemists. International Microbiology 8: 1321.

ARRUDA L et al. 2013. Screening of rhizobacteria isolated from maize (Zea mays L.) in Rio Grande do Sul State (South Brazil) and analysis of their potential to improve plant growth. Applied Soil Ecology 63: 15-22.

BANDICK AK \& DICK RP. 1999. Field management effects on soil enzyme activities. Soil Biology \& Biochemistry 31 : 1471-1479.

BURNS RG et al. 2013. Soil enzymes in a changing environment: current knowledge and future directions. Soil Biology \& Biochemistry 58: 216-234.

CANTERI MG et al. 2001. SASM-AGRI - Sistema para análise e separação de médias em experimentos agrícolas pelos métodos Scott-Knott, Tukey e Duncan. Revista Brasileira de Agrocomputação 1: 18-24.

CARDOSO EJBN \& NOGUEIRA MA. 2007. A rizosfera e seus efeitos na comunidade microbiana e na nutrição de plantas. In: SILVEIRA APD \& FREITAS SS. Microbiota do solo e qualidade ambiental. Campinas: Instituto Agronômico. p.79-96.

CENCIANI K et al. 2011. Enzymatic activity measured by microcalorimetry in soil amended with organic residues. Revista Brasileira de Ciência do Solo 35: 1167-1175.

CHAGAS JUNIOR AF et al. 2010. Capacidade de solubilização de fosfatos e eficiência simbiótica de rizóbios isolados de solos da Amazônia. Acta Scientiarum Agronomy 32: 359-366.

CORDEIRO MAS et al. 2012. Atributos bioquímicos e químicos do solo rizosférico e não rizosférico de culturas em rotação no sistema de semeadura direta. Revista Brasileira de Ciência do Solo 36: 1794-1803.

DAS SK \& VARMA A. 2011. Role of enzymes in maintaining soil health. In: SHUKLA G \& VARMA A. Soil Enzymology. 
Berlin: Springer-Verlag. p.25-42.

DJURIC $S$ et al. 2011. Selection of indigenous fluorescent pseudomonad isolates from maize rhizospheric soil in Vojvodina as possible PGPR. Romanian Biotechnological Letters 16: 6580-6590.

EMBRAPA. 2013. Empresa Brasileira de Pesquisa Agropecuária. Sistema Brasileiro de Classificação de Solos. 3ed. Rio de Janeiro: Embrapa Solos. 353p.

FIGUEROA-LÓPEZ AM et al. 2016. Rhizospheric bacteria of maize with potential for biocontrol of Fusarium verticillioides. SpringerPlus 5: 330 .

FISCHER SE et al. 2007. Isolation and characterization of bacteria from the rhizosphere of wheat. World Journal of Microbiology and Biotechnology 23: 895-903.

FREITAS VR \& PICOLI SU 2007. A coloração de Gram e as variações na sua execução. Newslab 82: 124-128.

GORLACH-LIRA K \& COUTINHO HDM. 2007. Population dynamics and extracellular enzymes activity of mesophilic and thermophilic bacteria isolated from semi-arid soil of northeastern Brazil. Brazilian Journal of Microbiology 38: $135-141$.

GHOSH A et al. 2007. Bacterial diversity of East Calcutta wet land area: possible identification of potential bacterial population for different biotechnological uses. Microbial Ecology 54: 452-459.

GYANESHWAR P et al. 2002. Role of soil microorganisms in improving P nutrition of plants. Plant and Soil 245: 83-93.

JEONG JH et al. 2010. Characterization of a multifunctional feather-degrading Bacillus subtilis isolated from forest soil. Biodegradation 21: 1029-1040.

JURBURG SD \& SALLES JF. 2015. Functional redundancy and ecosystem function - The soil microbiota as a case study. In: LO YH et al. Biodiversity in ecosystems - linking structure and function. Rijeka: Intech. p. 29-49.

KASANA RC et al. 2008. A rapid and easy method for the detection of microbial cellulases on agar plates using gram's iodine. Current Microbiology 57: 503-507.

KAUR A et al. 2012. Isolation, characterization and identification of bacterial strain producing amylase. Journal of Microbiology and Biotechnology Research 2: 573-579.

KHAN MS et al. 2007. Role of phosphate-solubilizing microorganisms in sustainable agriculture - a review. Agronomy for Sustainable Development 27: 29-43.

KUKLINSKY-SOBRAL J et al. 2004. Isolation and characterization of soybean-associated bacteria and their potential for plant growth promotion. Environmental Microbiology 6: 1244-1251.

LI X et al. 2014. Functional potential of soil microbial communities in the maize rhizosphere. PLOS ONE 9: article e112609.

MAKI M et al. 2009. The prospects of cellulase-producing bacteria for the bioconversion of lignocellulosic biomass. International Journal of Biological Sciences 5: 500-516.

MANHÃES CMC \& FRANCELINO FMA. 2013. Biota do solo e suas relações ecológicas com o sistema radicular. Nucleus 10: 127-137.

MANZOOR $\mathrm{M}$ et al. 2017. Isolation of phosphate solubilizing bacteria from maize rhizosphere and their potential for rock phosphate solubilization-mineralization and plant growth promotion. Geomicrobiology 34: 81-95.

MOREIRA FMS \& SIQUEIRA JO. 2006. Microbiologia e Bioquímica do Solo. 2.ed. Lavras: UFLA. 729p.

NAHAS E et al. 1997. Atividade microbiana e propriedades bioquímicas do solo resultantes da aplicação de gesso agrícola na cultura do repolho. Scientia Agricola 54: 160-166.

OLIVEIRA AN et al. 2006a. Enzimas hidrolíticas extracelulares de isolados de rizóbia nativos da Amazônia Central, Amazonas, Brasil. Ciência e Tecnologia de Alimentos 26: 853-860.

OLIVEIRA AN et al. 2006b. Atividade enzimática de isolados de rizóbia nativos da Amazônia Central crescendo em diferentes níveis de acidez. Ciência e Tecnologia de Alimentos 26: 204-210.

PASCON RC et al. 2011. Amylolytic microorganism from São Paulo Zoo composting: isolation, identification, and amylase production. Enzyme Research 2011: article 679624.

PEDRINHO EAN et al. 2010. Identificação e avaliação de rizobactérias isoladas de raízes de milho. Bragantia 69:905911.

PEREIRA SIA \& CASTRO PML. 2014. Diversity and characterization of culturable bacterial endophytes from Zea mays and their potential as plant growth-promoting agents in metal-degraded soils. Environmental Science and Pollution Research 21: 14110-14123.

RAMOS MLG et al. 2012. Efeito dos sistemas de manejo e plantio sobre a densidade de grupos funcionais de microrganismos, em solo de Cerrado. Bioscience Journal 28: 58-68.

RIFFEL A \& BRANDELLI A. 2006. Keratinolytic bacteria isolated from feather waste. Brazilian Journal of Microbiology 37: 395-399.

RODRIGUES AA et al. 2016. Isolation and selection of plant growth-promoting bacteria associated with sugarcane. Pesquisa Agropecuária Tropical 46: 149-158.

SANCHEZ S \& DEMAIN AL. 2011. Enzymes and bioconversions of industrial, pharmaceutical, and biotechnological significance. Organic Process Research \& Development 15: 224-230.

SANOMIYA LT \& NAHAS E. 2003. Microrganismos produtores de hidrolases envolvidos nas transformações dos compostos do carbono e do nitrogênio do solo. Ciência Rural 33:835-842.

SANTOS EO \& MARTINS MLL. 2003. Effect of the medium composition on formation of amylase by Bacillus sp. Brazilian Archives of Biology and Technology 46: 129-134.

SHAN Q et al. 2008. Soil enzymes activities and their indication for fertility of urban forest soil. Frontiers of Environmental Science \& Engineering in China 2: 218-223. 
SHARMA SB et al. 2013. Phosphate solubilizing microbes: sustainable approach for managing phosphorus deficiency in agricultural soils. SpringerPlus 2: article 587.

SILVA P \& NAHAS E. 2002. Bacterial diversity in soil in response to different plants, phosphate fertilizers and liming. Brazilian Journal of Microbiology 33: 304-310.

SOUCHIE EL \& ABBOUD ACS. 2007. Solubilização de fosfato por microrganismos rizosféricos de genótipos de Guandu cultivados em diferentes classes de solo. Semina: Ciências Agrárias 28: 11-18.

SZILAGYI-ZECCHIN VJ et al. 2014. Identification and characterization of endophytic bacteria from corn (Zea mays L.) roots with biotechnological potential in agriculture. AMB Express 4: article 26.

TURNBULL AL et al. 2012. Isolation of bacteria from the rhizosphere and rhizoplane of potato (Solanum tuberosum) grown in two distinct soils using semi selective media and characterization of their biological properties. American Journal of Potato Research 89: 294-305.

VIANA LT et al. 2011. Microbial communities in Cerrado soils under native vegetation subjected to prescribed fire and under pasture. Pesquisa Agropecuária Brasileira 46: 1665-1672. 